\title{
Residual renal function in chronic dialysis is not associated with reduced erythropoietin-stimulating agent dose requirements: a cross-sectional study
}

\author{
Elizabeth Helene Louw and Mogamat-Yazied Chothia * (D)
}

\begin{abstract}
Background: Anaemia is a very common problem in patients with end-stage kidney disease (ESKD) and the use of erythropoietin-stimulating agents (ESA) has revolutionised its treatment. Residual renal function (RRF) is associated with a reduction in ESA resistance and mortality in chronic dialysis. The primary aim was to establish whether RRF has an association with ESA dose requirements in ESKD patients receiving chronic dialysis.

Methods: A single center, cross-sectional study involving 100 chronic dialysis patients was conducted from December 2015 to May 2016. Participants were divided into two groups depending on presence of RRF, which was defined as a 24-h urine sample volume of $\geq 100 \mathrm{ml}$. Erythropoietin resistance index [ERI = total weekly ESA dose (IU)/weight (kg)/haemoglobin concentration $(\mathrm{g} / \mathrm{dL}]$ was used as a measure of ESA dose requirements.

Results: There was no difference in ERI between those with RRF as compared to those without (9.5 versus 11.0, respectively; $P=0.45$ ). Also, ERI did not differ between those receiving haemodialysis as compared with peritoneal dialysis (10.8 versus 10.2 , respectively; $P=0.84$ ) or in those using renin-angiotensin system (RAS) blockers as compared with no RAS blocker use (11.6 versus 9.2, respectively; $P=0.10$ ). Lower ERI was evident for those with cystic kidney disease as compared to those with other causes of ESKD (6.9 versus 16.5, respectively; $P=0.32$ ) although this did not reach statistical significance. Higher ERI was found in those with evidence of systemic inflammation as compared to those without (16.5 versus 9.5, respectively; $P=0.003$ ).
\end{abstract}

Conclusions: There was no association between RRF and ESA dose requirements, irrespective of dialysis modality, RAS blocker use, primary renal disease or hyperparathyroidism.

Keywords: Residual renal function, Erythropoietin resistance index, Chronic dialysis, Erythropoietin stimulating agent dose requirements

\section{Background}

Anaemia is a very common problem in end-stage kidney disease (ESKD) and has been reported to occur in up to $75 \%$ of patients at presentation [1]. The treatment of anaemia with erythropoietin-stimulating agents (ESA) in ESKD has revolutionised its treatment, but its use has been tempered by higher risks of cardiovascular morbidity and mortality [2]. This has resulted in a more

\footnotetext{
* Correspondence: yaziedc@sun.ac.za

Divisions of General Medicine and Nephrology, Department of Medicine,

Faculty of Medicine and Health Sciences, Stellenbosch University and

Tygerberg Academic Hospital, Cape Town 7505, South Africa
}

judicious prescription of ESA in chronic dialysis patients with more conservative haemoglobin $(\mathrm{Hb})$ target ranges. The focus of treatment of anaemia has shifted from reducing cardiovascular event rates to improving quality of life.

A recent meta-analysis found no difference in $\mathrm{Hb}$ concentrations between haemodialysis (HD) and peritoneal dialysis (PD) patients [3]; however, treatment response to ESA may vary depending on dialysis modality. It has been reported that PD patients tend to have lower ESA dose requirements than their HD counterparts $[4,5]$. Possible explanations for this include less frequent 
phlebotomy, subcutaneous administration of ESA that is associated with up to a third saving in dose and finally the preservation of residual renal function (RRF) [6]. The most common factors associated with increased dose requirements in chronic dialysis patients are iron deficiency and chronic inflammation. Other causes include malnutrition, hyperparathyroidism, poor vascular access, older age, dialysis vintage and use of reninangiotensin-system (RAS) blockers [7, 8].

A very important factor associated with reduced ESA dose requirements is RRF. There is no universally accepted definition for RRF, although most studies make use of a urine volume greater than $100 \mathrm{ml}$ to $250 \mathrm{ml}$ per day $[9,10]$. The CANUSA study reported that for every $250 \mathrm{ml}$ of urine output per day, mortality was reduced by $36 \%$ [9]. Other studies reported that the risk of death was reduced by $11-23 \%$ for each $1 \mathrm{ml} / \mathrm{min} / 1.73 \mathrm{~m}^{2}$ of $\operatorname{RRF}[10,11]$. It has been found that RRF is better preserved in PD than HD [12]. This may be due to improved haemodynamic stability during ultrafiltration in PD as compared to HD. Therefore, RRF may partially explain why PD patients have reduced ESA dose requirements as well as less ESA resistance.

Erythropoietin resistance index (ERI), which is defined as the weekly dose of ESA divided by patient weight and corrected for the $\mathrm{Hb}$ concentration, is a measure of a patient's response to ESA. It has become routine for studies to report ERI as a measure of ESA dose requirements. A recent study found that a strong linear relationship exists between ERI and weight-adjusted ESA dose using a universal formula [13]. However, it is important to take cognisance of the timing of the ESA initiation and the value of the accompanying $\mathrm{Hb}$ concentration when calculating the ERI. At the time of initiation, a higher ERI measurement may be evident as lower $\mathrm{Hb}$ concentrations may be present. As the $\mathrm{Hb}$ concentration increases in response to the ESA, the ERI will decrease [14]. Once target $\mathrm{Hb}$ concentrations are achieved, the ESA dose is unlikely to change and the ERI calculation will remain relatively constant. Therefore, an ERI which is high at the time of ESA initiation may wrongly be interpreted as ESA resistance. ERI should only be used in patients established on relatively constant ESA doses to avoid misinterpretation and inappropriate increases in dose. It has been reported that the ERI is significantly lower in patients with RRF when compared to those with anuria $[15,16]$.

The primary aim of this study was to establish whether RRF in chronic dialysis patients was associated with reduced ESA dose requirements using ERI as a measure of response. Secondary outcomes included comparisons of ERI between dialysis modality, route of ESA administration, primary renal disease and RAS blocker use.

\section{Methods}

\section{Study design, setting and participants}

A cross-sectional study involving 100 chronic HD and PD patients was undertaken at Tygerberg Academic Hospital and its associated satellite dialysis units in the Western Cape province of South Africa, during the period of December 2015 to May 2016. All chronic dialysis patients $\geq 18$ years of age, with the ability to give informed consent and on stable ESA treatment for at least 3 months were included. Patients were excluded if they were receiving dialysis for acute kidney injury or delayed graft function, actively bleeding, current infection or there was an inability to collect a 24-h urine sample (Fig. 1). All patients included were free of primary haematological diseases.

Data regarding demographics, primary renal disease, co-morbid diseases, dialysis modality and vintage, dry weight and drug prescription were collected from clinical records. Laboratory data collected included $\mathrm{Hb}$, albumin, ferritin, transferrin saturation, C-reactive protein (CRP) and parathyroid hormone (PTH). RRF was measured using a urine sample collected over 24-h. In HD patients, it was measured during the longest interdialytic period and in PD patients during any 24-h period.

The patients were then divided into two groups depending on presence or absence of RRF, defined as the production of at least $100 \mathrm{ml}$ of urine in $24 \mathrm{~h}$ (Fig. 1). ERI for each patient was calculated as the current weekly erythropoietin dose per kilogram of body weight (IU/kg/week) divided by the $\mathrm{Hb}$ concentration (g/dL). All the patients received ESA subcutaneously. Laboratory evidence of systemic inflammation was defined as the presence of all the following: a low serum albumin $(<35 \mathrm{~g} / \mathrm{L})$, raised serum CRP $(>10 \mathrm{mg} / \mathrm{L})$ and raised serum ferritin (> $150 \mathrm{ng} / \mathrm{mL}$ ). Hyperparathyroidism was classified according to the Kidney Disease Improving Global Outcomes (KDIGO) clinical practice guideline recommendations for the management of chronic kidney disease-mineral and bone disorder (CKD-MBD). Those with a PTH value of 2-9 times the upper limit of normal for the assay were regarded as being in the target range (17.0-76.5 pmol/L). Those with $\mathrm{PTH}<17.0 \mathrm{pmol} / \mathrm{L}$ or $>76.5 \mathrm{pmol} / \mathrm{L}$ were regarded as being over-suppressed or having hyperparathyroidism, respectively.

\section{Statistical analysis}

Means \pm standard deviations were used to summarize data with a normal distribution and medians and interquartile ranges (IQR) for data that did not have a normal distribution. Histograms, bar graphs and box-andwhisker plots were used where appropriate. Chi-squared and Fisher's exact tests were used to compare categorical data. Both unadjusted and adjusted analysis with multi- 


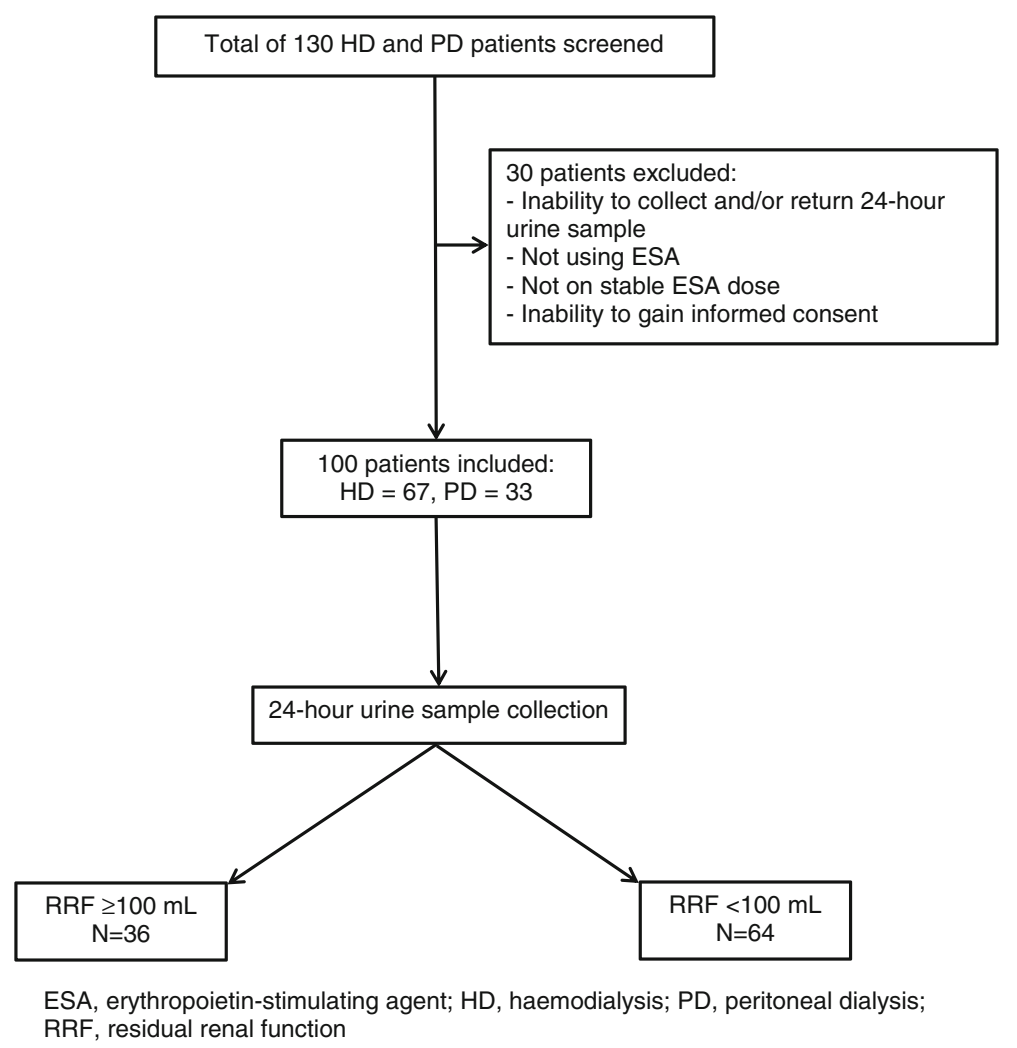

Fig. 1 Flow diagram of patients screened and included in the final analysis

linear regression for age, sex and race were used for dialysis modality, route of ESA administration, PTH status, RAS blocker use and primary renal disease. Where continuous variables had a normal distribution, t-tests were used to compare means, and if not normally distributed were analysed using Mann-Whitney-U tests. A significant $P$-value was set at $P<0.05$. SPSS version 24 was used for data analysis.

\section{Results}

A total of 100 patients were included in the final analysis. The mean for age was $41 \pm 10.5$ years and 57\% were female. Most of the patients were of mixed ancestry (65\%). The most common primary kidney disease was ESKD (cause unknown) (66\%), followed by renal vascular disease (14\%). Two-thirds (67\%) of the patients were receiving chronic $\mathrm{HD}$ as their dialysis modality while the rest were receiving chronic ambulatory PD.

A total of 36 patients had RRF. It was more common in $\mathrm{PD}$ patients than in those receiving $\mathrm{HD}$ as their dialysis modality $(58.3 \%$ versus $41.7 \%$, respectively; $P<$ 0.01 ). Patients with RRF were younger (37.4 versus 43.0 years old; $P=0.01$ ), and had a shorter dialysis vintage (34 versus 64 months; $P<0.01$ ). More patients with RRF were on diuretics $(75.0 \%$ versus $31.3 \%, P<0.01)$ and phosphate binders $(94.4 \%$ versus $73.4 \%, P=0.01)$. There was a trend toward less RAS blocker use in those with RRF as compared to those without (38.9\% versus $59.4 \%$, respectively; $P=0.05)$. There were no statistical significant differences in any of the laboratory serum measurements (Table 1).

With respect to our primary outcome, ERI did not differ in those with or without RRF (9.5 [IQR 7.0-15.3] versus 11.0 [IQR 6.3-16.2], respectively; $P=0.45$ ). The median dose of ESA was identical in each group (6000 IU per week). When dividing RRF into quartiles, there were no statistical differences in ERI between those with higher volumes of RRF as compared to those with lower volumes or no RRF $(P=0.82)$ (Figs. 2 and 3$)$. Also, a statistically significant association was not identified between ERI and RRF volume using linear regression analysis $(P=0.27)$.

ERI did not differ by dialysis modality (10.8 [IQR $8.5-$ 14.3] in PD versus 10.2 [IQR 5.9-16.0] in HD, $P=0.84$ ). Lower ERI were evident for those with cystic kidney disease as compared to those with other causes of ESKD (6.9 [IQR 3.9-13.2] versus 16.5 [IQR 12.0-17.9], respectively; $P=0.43$ ) but it did not reach statistical significance. There was no statistically significant difference in ERI in those with or without RAS blocker use (11.6 [IQR 7.9-16.7] versus 9.2 [IQR 6.1-15.2], respectively; $P=0.10)$. 
Table 1 Comparisons of clinical baseline characteristics in those with and without RRF

\begin{tabular}{|c|c|c|c|c|c|}
\hline \multirow{2}{*}{$\begin{array}{l}\text { Parameter } \\
\text { Number of patients }\end{array}$} & \multicolumn{2}{|c|}{ RRF present } & \multicolumn{2}{|c|}{ RRF absent } & \multirow{2}{*}{$\frac{P \text {-value }}{-}$} \\
\hline & 36 & & 64 & & \\
\hline Age in years, mean $\pm S D$ & 37.4 & \pm 10.7 & 43 & \pm 10.2 & 0.01 \\
\hline \multicolumn{6}{|l|}{ Sex, n (\%) } \\
\hline Male & 15 & $(41.7)$ & 28 & $(43.8)$ & \multirow[t]{2}{*}{0.84} \\
\hline Female & 21 & $(58.3)$ & 36 & $(56.3)$ & \\
\hline \multicolumn{6}{|l|}{ Race, n (\%) } \\
\hline Mixed ancestry & 23 & $(63.9)$ & 42 & $(65.6)$ & \multirow[t]{4}{*}{0.15} \\
\hline Caucasian & 6 & $(16.7)$ & 16 & $(25.0)$ & \\
\hline Black & 5 & $(13.9)$ & 6 & $(9.4)$ & \\
\hline Indian & 2 & $(5.6)$ & 0 & $(0)$ & \\
\hline \multicolumn{6}{|l|}{ Underlying kidney disease, n (\%) } \\
\hline ESKD (cause unknown) & 23 & $(63.9)$ & 43 & $(67.2)$ & \multirow[t]{5}{*}{0.78} \\
\hline Renal vascular disease & 6 & $(16.7)$ & 8 & $(12.5)$ & \\
\hline Cystic kidney disease & 1 & $(2.8)$ & 3 & $(4.7)$ & \\
\hline Autoimmune disease & 2 & $(5.6)$ & 2 & $(3.1)$ & \\
\hline Other and unknown & 4 & $(11.1)$ & 8 & $(12.5)$ & \\
\hline \multicolumn{6}{|l|}{ Mode of dialysis, $n(\%)$} \\
\hline $\mathrm{HD}$ & 15 & $(41.7)$ & 52 & $(81.3)$ & \multirow[t]{2}{*}{$<0.01$} \\
\hline PD & 21 & $(58.3)$ & 12 & $(18.8)$ & \\
\hline Dialysis vintage (months) & 34 & $(10.5-53)$ & 64 & $(41-125)$ & $<0.01$ \\
\hline ESA dose (IU per week) & 6000 & $(5000-6000)$ & 6000 & $(3000-9000)$ & 0.46 \\
\hline \multicolumn{6}{|c|}{ Route of ESA administration, $\mathrm{n}(\%)$} \\
\hline SC & 36 & $(100)$ & 64 & $(100)$ & - \\
\hline \multicolumn{6}{|l|}{ Chronic medication, n (\%) } \\
\hline RAS blocker & 14 & $(38.9)$ & 38 & $(59.4)$ & 0.05 \\
\hline Diuretic & 27 & $(75.0)$ & 20 & $(31.3)$ & $<0.01$ \\
\hline Phosphate binder & 34 & $(94.4)$ & 47 & $(73.4)$ & 0.01 \\
\hline Vitamin D & 9 & $(25.0)$ & 27 & $(37.5)$ & 0.08 \\
\hline Iron therapy & 35 & $(97.2)$ & 63 & $(98.4)$ & 0.46 \\
\hline Oral & 31 & $(86.1)$ & 50 & $(78.1)$ & \\
\hline IV & 4 & $(11.1)$ & 13 & $(20.3)$ & \\
\hline \multicolumn{6}{|l|}{ Laboratory parameters } \\
\hline Haemoglobin (g/dL) & 10.1 & $(9.2-11.1)$ & 10.1 & $(8.8-10.8)$ & 0.54 \\
\hline Albumin $(\mathrm{g} / \mathrm{L})$ & 39 & $(34-40)$ & 37 & $(33-40)$ & 0.28 \\
\hline Ferritin $(\mathrm{ng} / \mathrm{mL})$ & 545.0 & $(299-759.5)$ & 469.0 & $(237.5-781.5)$ & 0.99 \\
\hline Transferrin saturation (\%) & 22 & $(15-30)$ & 23 & $(16-29)$ & 0.49 \\
\hline CRP (mg/L) & 15 & $(4-29)$ & 20 & $(4-45)$ & 0.48 \\
\hline PTH (pmol/L) & 41.5 & $(18.6-73.2)$ & 50.2 & $(17.6-117.4)$ & 0.70 \\
\hline Systemic inflammation, n (\%) & 3 & $(8.3)$ & 11 & $(17.1)$ & 0.21 \\
\hline
\end{tabular}

Values expressed in a range in parentheses refer to interquartile ranges; single values refer to percentage of the group population. RRF residual renal function; $S D$ standard deviation; ESKD end-stage kidney disease; HD haemodialysis; PD peritoneal dialysis; ESA erythropoietin-stimulating agent; IU international units; SC subcutaneous; RAS renin angiotensin system; CRP C-reactive protein; $P T H$ parathyroid hormone. Systemic inflammation was defined as serum ferritin $>150 \mathrm{ng} / \mathrm{mL}$ and serum $\mathrm{CRP}>10 \mathrm{mg} / \mathrm{L}$ and serum albumin $<35 \mathrm{~g} / \mathrm{L}$ 


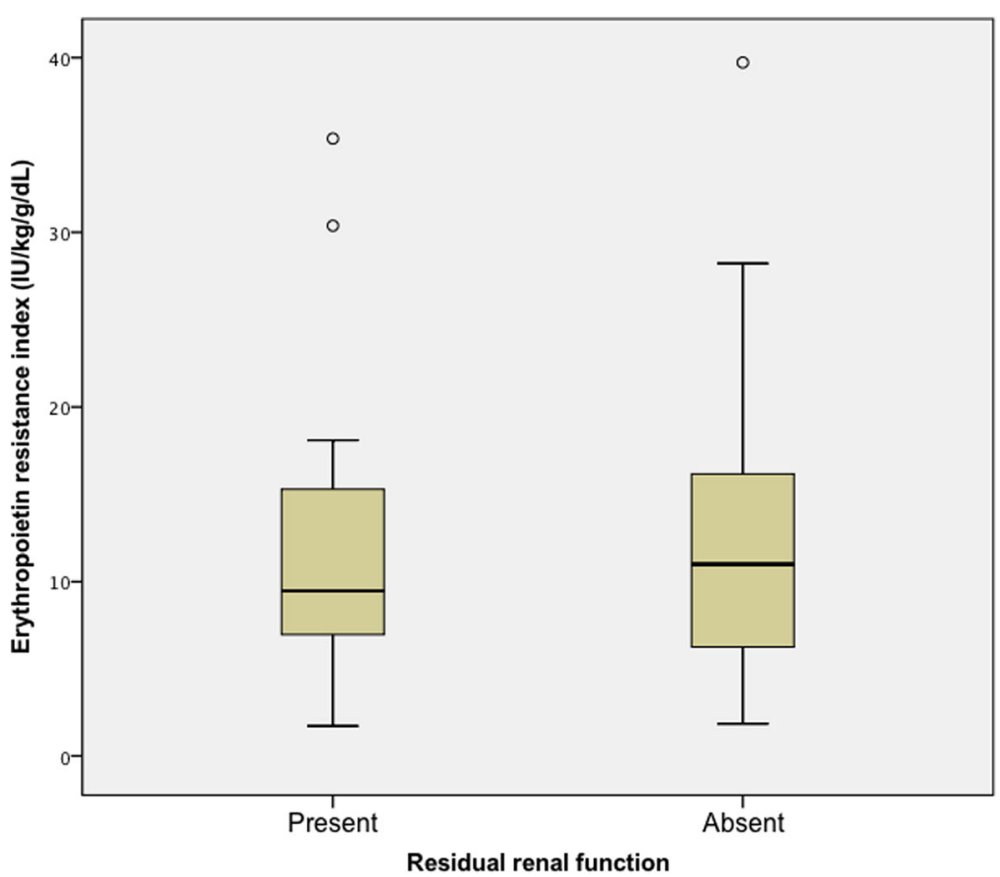

Fig. 2 Primary outcome: Erythropoietin resistance index and residual renal function

A total of 14 patients fulfilled our criteria for systemic inflammation. Of these, 11 (78.6\%) had no RRF and had higher ERI when compared to those without systemic inflammation (16.5 [IQR 11.0-18.7] versus 9.5 [IQR 6.0-14.9], respectively; $\quad P=0.003) . \quad$ A statistically significant association between ERI and systemic inflammation persisted after adjusting for dialysis vintage using multiple linear regression, $P=0.049)$. When comparing ERI with PTH $<17.0 \mathrm{pmol} / \mathrm{L}$ (over-suppressed), 17.0$76.5 \mathrm{pmol} / \mathrm{L}$ (target range) and $>76.5 \mathrm{pmol} / \mathrm{L}$

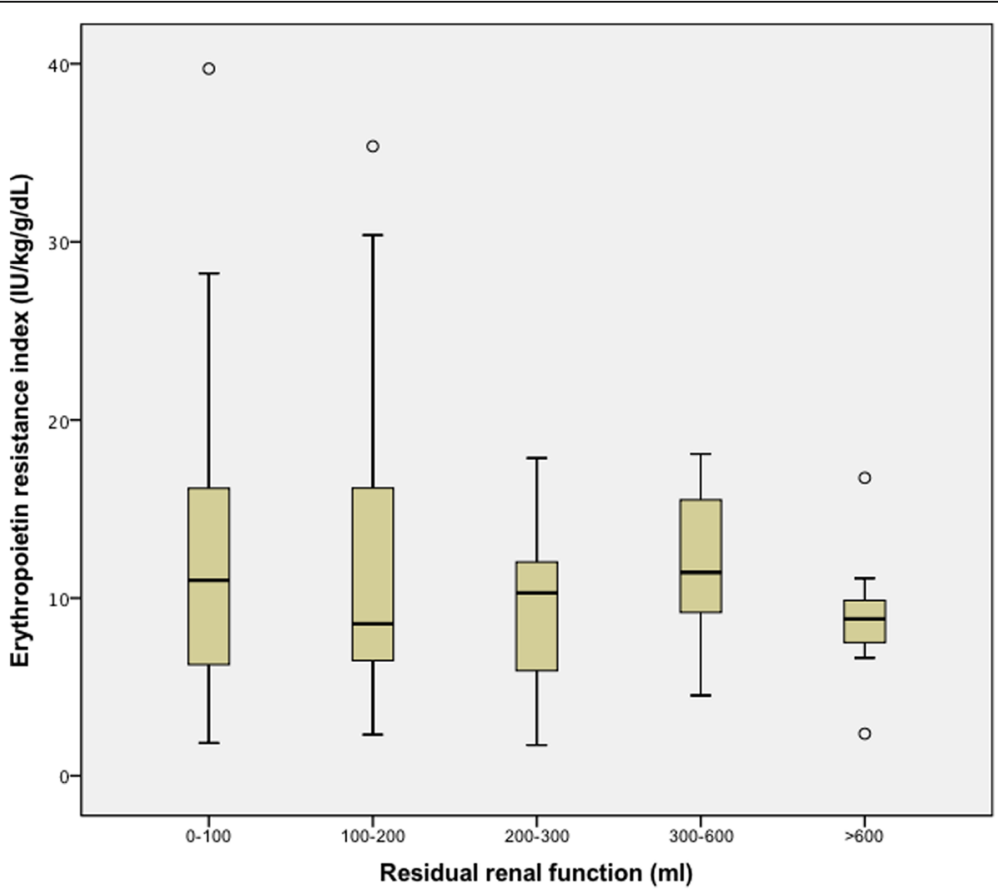

Fig. 3 A comparison of quartiles of residual renal function and its association with erythropoietin resistance index 
(hyperparathyroidism), ERI tended to be higher in the over suppressed group but there were no statistical significant differences (Tables 2 and 3).

\section{Discussion}

In our study, we found no association between RRF and ESA dose requirements as measured using ERI. This finding contrasts with some larger studies that identified less ESA requirements in those patients with preserved RRF $[15,16]$. These studies were done mainly in HD

Table 2 Primary and secondary outcomes

\begin{tabular}{|c|c|c|c|c|}
\hline Parameter & $\begin{array}{l}\text { Number of } \\
\text { patients }\end{array}$ & Median ERI & IQR & $P$-value \\
\hline \multicolumn{5}{|l|}{ Primary Outcome } \\
\hline \multicolumn{5}{|c|}{ Residual renal function } \\
\hline Present & 36 & 9.5 & $(7.0-15.3)$ & \multirow[t]{2}{*}{0.45} \\
\hline Absent & 64 & 11.0 & $(6.3-16.2)$ & \\
\hline \multicolumn{5}{|l|}{ Secondary Outcomes } \\
\hline \multicolumn{5}{|l|}{ Dialysis modality } \\
\hline $\mathrm{HD}$ & 67 & 10.8 & $(8.5-14.3)$ & \multirow[t]{2}{*}{0.84} \\
\hline PD & 33 & 10.2 & $(5.9-16.0)$ & \\
\hline RAS blocker use & 52 & 11.6 & $(7.9-16.7)$ & \\
\hline ACE inhibitor & 43 & 11.8 & $(8.1-16.8)$ & \multirow[t]{3}{*}{0.10} \\
\hline ARB & 9 & 11.0 & $(6.0-13.7)$ & \\
\hline $\begin{array}{l}\text { No RAS blocker } \\
\text { use }\end{array}$ & 48 & 9.2 & $(6.1-15.2)$ & \\
\hline \multicolumn{5}{|c|}{ PTH category (pmol/L) } \\
\hline$<17$ & 19 & 13.5 & $(6.5-16.8)$ & \multirow[t]{3}{*}{0.73} \\
\hline $17-76.5$ & 34 & 9.6 & $(6.2-14.9)$ & \\
\hline$>76.5$ & 28 & 9.1 & $(6.8-15.3)$ & \\
\hline \multicolumn{5}{|c|}{ Systemic inflammation } \\
\hline Present & 14 & 16.5 & $(11.0-18.7)$ & \multirow[t]{2}{*}{$<0.01$} \\
\hline Absent & 86 & 9.5 & $(6.0-14.9)$ & \\
\hline \multicolumn{5}{|c|}{ Underlying kidney disease } \\
\hline $\begin{array}{l}\text { ESKD (cause } \\
\text { unknown) }\end{array}$ & 66 & 10.8 & $(7.8-15.4)$ & \multirow[t]{5}{*}{0.32} \\
\hline $\begin{array}{l}\text { Renal vascular } \\
\text { disease }\end{array}$ & 14 & 8.4 & $(5.2-14.3)$ & \\
\hline $\begin{array}{l}\text { Cystic kidney } \\
\text { disease }\end{array}$ & 4 & 6.9 & $(3.9-13.2)$ & \\
\hline $\begin{array}{l}\text { Autoimmune } \\
\text { disease }\end{array}$ & 4 & 16.5 & $(12.0-17.9)$ & \\
\hline $\begin{array}{l}\text { Other and } \\
\text { unknown }\end{array}$ & 12 & 9.1 & $(6.4-15.5)$ & \\
\hline
\end{tabular}

$E R /$ erythropoietin resistance index; IQR interquartile range; $H D$ haemodialysis; $P D$ peritoneal dialysis; $A C E$ angiotensin-converting enzyme; $R A S$ renin angiotensin system; PTH parathyroid hormone; ESKD end-stage kidney disease. 'Other' refers to reflux nephropathy, single kidney, renal cortical necrosis, pre-eclampsia, drug overdose and unknown aetiology. Systemic inflammation was defined as serum ferritin $>150 \mathrm{ng} / \mathrm{mL}$ and serum CRP $>10 \mathrm{mg} / \mathrm{L}$ and serum albumin $<35 \mathrm{~g} / \mathrm{L}$ patients. Another study that was conducted in PD patients reported no influence of RRF on ERI [17]. A recent, large observational study reported that ERI was higher for patients on HD as compared to those on PD [5]. It is unclear whether patients included were on stable ESA doses and what the effect RRF may have had. However, the authors mention that more frequent phlebotomy and the intravenous administration of ESA might have elevated the ESA dose requirements in the HD group. In contrast, all our participants received ESA by the subcutaneous route and were on stable ESA doses for at least 3 months prior to recruitment therefore limiting the effect that these two potential confounding variables may have had on ERI.

Our study population was younger and mainly of mixed ancestry when compared to other studies $[18,19]$. Most were receiving HD with fewer PD patients included due to logistical issues related to the collection and/or the return of 24-h urine samples and an inability to obtain informed consent. RRF was mostly present in our PD patients who also had the shortest dialysis vintage. These findings reflect our PD-first policy.

We found a strong association between higher ERI and laboratory evidence of systemic inflammation. Others have reported similar findings [5, 17]. None of our patients were iron deficient or had an obvious infection. This systemic inflammation could possibly be due to occult infection or dialysis-related factors. We have previously reported a strong association between occult periodontal disease and systemic inflammation in our chronic dialysis population [20]. A high ERI may therefore be a marker of systemic inflammation and clinicians should be cautious when deciding to increase the ESA dose, as this class of drugs has been associated with increased risk of cardiovascular events.

We found no association between ERI and dialysis modality, RAS blocker use, the underlying primary renal disease or hyperparathyroidism. A recent meta-analysis also reported no difference relative to dialysis modality [3], although some individual studies have reported differences $[4,5]$. There was a trend toward less RRF in those with RAS blocker use. Although there have been studies suggesting that RAS blocker use may preserve RRF, others have found no benefit $[21,22]$. It may be that better volume control in those with RRF resulted in less prescription of antihypertensive drugs including RAS blockers. RAS blockers had no significant effect on ERI. The influence of RAS blockers on ESA resistance remains controversial. Various pathogenic mechanisms have been implicated [23, 24]; however, observational studies have reported mixed results [25-27]. Nonetheless, a dose-response relationship does exist [28] and therefore when other common causes for ESA resistance 
Table 3 Comparisons of clinical parameters between dialysis modalities

\begin{tabular}{|c|c|c|c|c|c|}
\hline \multirow{2}{*}{$\begin{array}{l}\text { Parameter } \\
\text { Number of patients }\end{array}$} & \multicolumn{2}{|c|}{ Haemodialysis } & \multicolumn{2}{|c|}{ Peritoneal dialysis } & \multirow{2}{*}{$\frac{P \text {-value }}{-}$} \\
\hline & 67 & - & 33 & - & \\
\hline \multicolumn{6}{|c|}{ Residual renal function, n (\%) } \\
\hline Present & 15 & $(22.4)$ & 21 & $(63.6)$ & \multirow[t]{2}{*}{$<0.01$} \\
\hline Absent & 52 & $(77.6)$ & 12 & $(36.4)$ & \\
\hline Dialysis vintage (months) & 70 & $(41-125)$ & 14.5 & $(10-47)$ & $<0.01$ \\
\hline Haemoglobin (g/dL) & 10.1 & $(9.3-11)$ & 9.5 & $(7.9-10.8)$ & 0.05 \\
\hline ESA dose per week (IU) & 6000 & $(6000-10,000)$ & 6000 & $(6000-6000)$ & 0.16 \\
\hline ERI & 10.79 & $(5.93-16.02)$ & 10.20 & $(8.06-14.25)$ & 0.84 \\
\hline
\end{tabular}

Values expressed in a range in parentheses refer to interquartile ranges; single values refer to percentage of the total population. ESA erythropoietin-stimulating agent; $E R I$ erythropoietin resistance index

have not been identified, reducing or stopping RAS blockers is a reasonable next step.

The lower ERI in polycystic kidney disease patients is expected as it is thought that interstitial cells adjacent to the walls of the proximal-type cysts can produce erythropoietin, resulting in higher $\mathrm{Hb}$ concentrations and therefore lower ESA requirements [29]. Our patients with autoimmune disease tended to have higher ERI that may be related to systemic inflammation.

Hyperparathyroidism is frequently listed as a cause for ESA resistance; however, we did not identify any association with PTH level. In fact, our patients classified as having secondary hyperparathyroidism tended to have a lower ERI. It is thought that the high-turnover bone disease from secondary hyperparathyroidism may cause bone marrow fibrosis. This has not been found in animal models of secondary hyperparathyroidism [30] and it therefore seems increasingly unlikely that hyperparathyroidism contributes to ESA resistance.

\section{Strengths and limitations}

Our study has some limitations. This was a relatively small, single center study, with fewer PD patients. The inclusion of 24-h urine sample creatinine clearance and/ or $\beta 2$-microglobulin may have better characterised RRF. However, the interpretation of our ERI measurements is more reliable because of the uniform route of ESA administration and the inclusion of only those on relatively stable ESA doses.

\section{Conclusions}

In summary, we found no association between RRF and ESA dose requirements as measured using ERI, irrespective of dialysis modality, RAS blocker use, primary renal disease or hyperparathyroidism. However, the presence of systemic inflammation had a significant effect on ERI. Therefore, in those with high ESA dose requirements, an active search for a source of inflammation should be conducted.

\section{Abbreviations}

CANUSA: Canada-USA Peritoneal Dialysis Study; CKD-MBD: Chronic kidney disease-mineral and bone disorder; CRP: C-reactive protein; ERI: Erythropoietin resistance index; ESA: Erythropoietin-stimulating agents; ESKD: End-stage kidney disease; Hb: Haemoglobin; HD: Haemodialysis; IQR: Interquartile range; KDIGO: Kidney Disease Improving Global Outcomes; PD: Peritoneal dialysis; PTH: Parathyroid hormone; RAS: Renin-angiotensin-system; RRF: Residual renal function

\section{Acknowledgements}

We would like to thank the Renal Unit nursing staff at Tygerberg Academic Hospital for assisting with patient recruitment and collection of 24-h urine samples. We are grateful to Prof MR Davids for proofreading the final manuscript.

\section{Funding}

None (self-funded).

\section{Authors' contributions}

EHL and MYC were involved in the conceptualisation, study design, data collection, statistical analysis and drafting of the manuscript. Both authors read and approved the final manuscript.

Ethics approval and consent to participate

This study was approved by the Human Research Ethics Committee of Stellenbosch University (study number S15/04/070) and was conducted in accordance with the Declaration of Helsinki. All patients included gave written informed consent.

Consent for publication

Not applicable to this study.

\section{Competing interests}

The authors have no competing interests to declare.

\section{Publisher's Note}

Springer Nature remains neutral with regard to jurisdictional claims in published maps and institutional affiliations.

Received: 13 April 2017 Accepted: 14 November 2017

Published online: 25 November 2017

\section{References}

1. McClellan W, Aronoff SL, Bolton WK, Hood S, Lorber DL, Tang KL, Tse TF, Wasserman B, Leiserowitz M. The prevalence of anemia in patients with chronic kidney disease. Curr Med Res Opin. 2004;20(9):1501-10.

2. Zhang Y, Thamer M, Stefanik K, Kaufman J, Cotter DJ. Epoetin requirements predict mortality in hemodialysis patients. Am J Kidney Dis. 2004;44(5):866-76.

3. Wang W, Zhang W, Sun T, Ma F, Su S, Xu Z. Effect of peritoneal dialysis versus hemodialysis on renal anemia in renal in end-stage disease patients: a meta-analysis. Ren Fail. 2017;39(1):59-66.

4. Duong U, Kalantar-Zadeh K, Molnar MZ, Zaritsky JJ, Teitelbaum I, Kovesdy $C P$, Mehrotra R. Mortality associated with dose response of erythropoiesis- 
stimulating agents in hemodialysis versus peritoneal dialysis patients. Am J Nephrol. 2012;35(2):198-208.

5. Bae MN, Kim SH, Kim YO, Jin DC, Song HC, Choi EJ, Kim Y, Kim Y, Kang S, Kim N. Association of erythropoietin-stimulating agent responsiveness with mortality in hemodialysis and peritoneal dialysis patients. PLoS One. 2015;10(11):e0143348.

6. Snyder JJ, Foley RN, Gilbertson DT, Vonesh EF, Collins AJ. Hemoglobin levels and erythropoietin doses in hemodialysis and peritoneal dialysis patients in the United States. J Am Soc Nephrol. 2004;15(1):174-9.

7. Johnson DW, Pollock CA, Macdougall IC. Erythropoiesis-stimulating agent hyporesponsiveness (review article). Nephrology. 2007;12(4):321-30.

8. Gilbertson DT, Peng Y, Arneson TJ, Dunning S, Collins AJ. Comparison of methodologies to define hemodialysis patients hyporesponsive to epoetin and impact on counts and characteristics. BMC Nephrol. 2013;14(1):44.

9. Bargman JM, Thorpe KE, Churchill DN, CANUSA Peritoneal Dialysis Study Group. Relative contribution of residual renal function and peritoneal clearance to adequacy of dialysis: a reanalysis of the CANUSA study. J Am Soc Nephrol. 2001;12(10):2158-62.

10. Termorshuizen F, Korevaar JC, Dekker FW, van Manen JG, Boeschoten EW, Krediet RT, NECOSAD Study Group. The relative importance of residual renal function compared with peritoneal clearance for patient survival and quality of life: an analysis of the Netherlands cooperative study on the adequacy of dialysis (NECOSAD)-2. Am J Kidney Dis. 2003;41(6):1293-302.

11. Paniagua R, Amato D, Vonesh E, Correa-Rotter R, Ramos A, Moran J, Mujais S, Mexican Nephrology Collaborative Study Group. Effects of increased peritoneal clearances on mortality rates in peritoneal dialysis: ADEMEX, a prospective, randomized, controlled trial. J Am Soc Nephrol. 2002;13(5): 1307-20.

12. Jansen MA, Hart AA, Korevaar JC, Dekker FW, Boeschoten EW, Krediet RT. Predictors of the rate of decline of residual renal function in incident dialysis patients. Kidney Int. 2002;62(3):1046-53.

13. Chait $Y$, Kalim S, Horowitz J, Hollot CV, Ankers ED, Germain MJ, Thadhani RI. The greatly misunderstood erythropoietin resistance index and the case for a new responsiveness measure. Hemodial Int. 2016;20(3):392-8.

14. Chait Y, Horowitz J, Nichols B, Shrestha RP, Hollot CV, Germain MJ. Controlrelevant erythropoiesis modeling in end-stage renal disease. IEEE Trans Biomed Eng. 2014;61(3):658-64.

15. Penne EL, van der Weerd NC, Grooteman MP, Mazairac AH, van den Dorpel MA, Nube MJ, Bots ML, Levesque R, ter Wee PM, Blankestijn PJ, CONTRAST investigators. Role of residual renal function in phosphate control and anemia management in chronic hemodialysis patients. Clin J Am Soc Nephrol. 2011;6(2):281-9.

16. Shafi T, Jaar BG, Plantinga LC, Fink NE, Sadler JH, Parekh RS, Powe NR, Coresh J. Association of residual urine output with mortality, quality of life, and inflammation in incident hemodialysis patients: the choices for healthy outcomes in caring for end-stage renal disease (CHOICE) study. Am J Kidney Dis. 2010;56(2):348-58.

17. Pajek J, Bučar-Pajek M, Grego K, Guček A, Bevc S, Ekart R, Vujkovac B, GolobKosmina P, Kandus A, Bren AF. Epoetin responsiveness in peritoneal dialysis patients: a multi-center Slovenian study. Ther Apher Dial. 2005;9(3):228-32.

18. SJ MN, Casula A, Shaw C, Castledine C. UK renal registry 18th annual report: chapter 2 UK renal replacement therapy prevalence in 2014: national and Centre-specific analyses. Nephron. 2016;132(Suppl 1):41-68.

19. Bamgboye EL. The challenges of ESRD care in developing economies: subSaharan African opportunities for significant improvement. Clin Nephrol. 2016;86((2016)(13)):18-22

20. Nadeem M, Stephen L, Schubert C, Davids M. Association between periodontitis and systemic inflammation in patients with end-stage renal disease. S Afr Dent J. 2009;64(10):470-3.

21. Moist LM, Port FK, Orzol SM, Young EW, Ostbye T, Wolfe RA, HulbertShearon $T$, Jones CA, Bloembergen WE. Predictors of loss of residual renal function among new dialysis patients. J Am Soc Nephrol. 2000;11(3):556-64.

22. Kolesnyk I, Noordzij M, Dekker FW, Boeschoten EW, Krediet RT. Treatment with angiotensin II inhibitors and residual renal function in peritoneal dialysis patients. Perit Dial Int. 2011;31(1):53-9.

23. Rieger KJ, Saez-Servent N, Papet MP, Wdzieczak-Bakala J, Morgat JL, Thierry J, Voelter W, Lenfant M. Involvement of human plasma angiotensin Iconverting enzyme in the degradation of the haemoregulatory peptide $\mathrm{N}$ acetyl-seryl-aspartyl-lysyl-proline. Biochem J. 1993;296(Pt 2):373-8.

24. Le Meur Y, Lorgeot V, Comte L, Szelag J, Aldigier J, Leroux-Robert C, Praloran V. Plasma levels and metabolism of AcSDKP in patients with chronic renal failure: relationship with erythropoietin requirements. Am J Kidney Dis. 2001;38(3):510-7.

25. Macdougall IC. The role of ACE inhibitors and angiotensin II receptor blockers in the response to epoetin. Nephrol Dial Transplant. 1999;14(8): 1836-41.

26. Saudan P, Halabi G, Perneger T, Wasserfallen J, Wauters J, Martin P, Western Switzerland Dialysis G. ACE inhibitors or angiotensin II receptor blockers in dialysed patients and erythropoietin resistance. J Nephrol. 2006;19(1):91.

27. Vlahakos DV, Marathias KP, Madias NE. The role of the renin-angiotensin system in the regulation of erythropoiesis. Am J Kidney Dis. 2010;56(3):558-65.

28. Marathias K, Agroyannis B, Mavromoustakos T, Matsoukas J, Vlahakos D. Hematocrit-lowering effect following inactivation of renin-angiotensin system with angiotensin converting enzyme inhibitors and angiotensin receptor blockers. Curr Top Med Chem. 2004;4(4):483-6.

29. Shah A, Molnar MZ, Lukowsky LR, Zaritsky JJ, Kovesdy CP, Kalantar-Zadeh K. Hemoglobin level and survival in hemodialysis patients with polycystic kidney disease and the role of administered erythropoietin. Am J Hematol. 2012;87(8):833-6.

30. Trunzo JA, McHenry CR, Schulak JA, Wilhelm SM. Effect of parathyroidectomy on anemia and erythropoietin dosing in end-stage renal disease patients with hyperparathyroidism. Surgery. 2008;144(6):915-9.

\section{Submit your next manuscript to BioMed Central and we will help you at every step:}

- We accept pre-submission inquiries

- Our selector tool helps you to find the most relevant journal

- We provide round the clock customer support

- Convenient online submission

- Thorough peer review

- Inclusion in PubMed and all major indexing services

- Maximum visibility for your research

Submit your manuscript at www.biomedcentral.com/submit
) Biomed Central 